\section{International Scientific Journal Theoretical \& Applied Science}

p-ISSN: 2308-4944 (print) e-ISSN: 2409-0085 (online)

Year: $2015 \quad$ Issue: 12 Volume: 32

Published: $30.12 .2015 \quad$ http://T-Science.org
Elena Pavlovna Ananeva

Ph.D., associate professor. Doctoral student in Department of Philosophy, Sociology and Management of socio-cultural activities State institution "Pivdennoukrainsky National Pedagogical University, named after K. D. Ushinsky" (SI PNPU named after K. D. Ushinsky) filosvit@mail.ru

SECTION 30. Philosophy.

\title{
METHODOLOGICAL ASPECTS RESEARCH OF MULTICULTURALISM
}

\begin{abstract}
The article considers the possibility of studying the phenomenon of multiculturalism means of modern methodology. Methodological aspects of the study of multiculturalism presented as a basis of social and philosophical concepts of the global socio-cultural space.

Key words: cultural diversity, methodological aspect, multiculturalism, multicultural paradigm, multicultural practice, the policy of multiculturalism, social and cultural space.

Language: Russian

Citation: Ananeva EP (2015) METHODOLOGICAL ASPECTS RESEARCH OF MULTICULTURALISM. ISJ Theoretical \& Applied Science 12 (32): 48-54.
\end{abstract}

Soi: http://s-o-i.org/1.1/TAS-12-32-9 Doi: crossef http://dx.doi.org/10.15863/TAS.2015.12.32.9

\section{УДК 172.3}

\section{МЕТОДОЛОГИЧЕСКИЕ АСПЕКТЫ ИССЛЕДОВАНИЯ МУЛЬТИКУЛЬТУРАЛИЗМА}

Аннотация: В статье рассматривается возможность исследования феномена мультикультурализма средствами современной методологии. Методологические аспекты изучения мультикультурализма представлены как основа формирования сочиально-философских концепциий глобального сочиокультурного пространства.

Ключевые слова: культурное разнообразие, методологический аспект, мультикультурализм, мультикультурная парадигма, мультикультурные практики, политика мультикультурализма, соииокультурное пространство.

Возможности

социокультурного пространства в формировании высокого уровня согласия в эпоху глобализации достаточно велики. Еще недавно методология исследования большинства феноменов средствами социальнофилософского знания выстраивалась в инновационной парадигме. Однако в инновационных амбициях имеет место деструктивное начало, которое нельзя игнорировать. В условиях глобальных изменений это деструктивное начало может быть трансформировано в креативный фактор с помощью синергетики, где достижение устойчивого равновесия в социальном развитии обусловлено коэволюцией рациональных инноваций и социокультурных традиций. Это помогает вывести инновационную практику и инновационное общество из тупиков цивилизационных противопоставлений на путь продуктивной модернизации.

Синергетический подход базируется на основных принципах: природа иерархически структурирована в несколько видов открытых нелинейных систем; связь между ними осуществляется через неравновесное состояние систем; неравновесность является необходимым условием появления новых систем, то есть развития. Развивающиеся системы открыты и обмениваются энергией и веществом с внешней средой. Исходя из этих положений, синергетический подход в социокультурном развитии - это очередной шаг к пониманию феномена человека во всех его разнообразных проявлениях, к раскрытию тайн всего многообразия творчества, коммуникации, процесса встраивания человека в природную, социальную и культурную среду. В основе 
данного подхода лежат такие качества личности, как склонность к компромиссам (толерантность), принятие «иного», ответственность перед будущим. Синергетически сформированные интеллектуальные конструкты помогают личности разрушить уходящий в древность стереотип страха перед неопределенностью и хаосом развития, увидеть красоту двойственности бытия, конструктивность и деструктивность неравновесия мира и общества [1, с. 427-428]. Следуя принципам синергетики, современное социально-философское знание предполагает важное в методологическом отношении феноменологическое и категориально-понятийное осмысление явлений ментального плана, к числу которых относится феномен мультикультурализма.

Культура постмодерна, узаконившая множественность в качестве всеобщего начала, устойчиво рассматривает мультикультурализм как наиболее допустимое культурное состояние общества, в котором толерантность к многообразию становится общественно преобладающей ценностью. При этом первые результаты политики мультикультурализма были далеко не однозначными. С одной стороны, государства, обратившиеся к принципам мультикультурализма, добились немалых успехов в ходе демократизации собственных обществ (Канада, Австралия, США, Швеция). Идеал сосуществования различных культурных стилей немало способствовал изменению общественного климата, утверждению духа терпимости к «иному», осмыслению правовой и бытийной равноценности разнообразных типов жизненного устройства. Однако необходимо отметить, что мультикультурализм в виде официальной культурно-политической парадигмы достигал хорошего результата лишь в том случае, когда последовательно проводился именно как стратегия. Поэтому, по нашему мнению, именно благодаря последовательности введения практики мультикультурализма, например, в Австралии, где она понималась как целостный политико-культурный проект, эта практика оказалась успешной. Неуспешным мультикультурализм становился в условиях его фрагментарного применения: когда производились лишь незначительные попытки мультикультурализации. Так, политика мультикультурализма в Канаде также в целом была удачна, т.к. способствовала снижению опасности восприятия чуждых культурных проявлений. Социальные мультикультурные программы предоставили возможность самореализации этнокультурным группам, что позволило им пройти социализацию, не меняя своих ценностно-смысловых представлений. Отрицательные факторы канадского мультикультурализма выразились в «позитивной дискриминации», которая предоставила этнокультурным группам более значительные социальные льготы, чем это было необходимо. Хотя в целом опыт самых разных стран показал, что мультикультурализм был выбран в них в качестве политико-культурной стратегии только после того, когда иные методы управления культурными различиями не оправдали себя. Таким образом, современное сообщество пришло к заключению, что основная идея мультикультурализма достигает положительных результатов, когда имеется отношение к культурным различиям не столько как к ценности, которую надо сохранить любой ценой, но как к реальности, которой нельзя избежать, но которая, тем не менее, не противостоит целям социального корпоративизма и интеграции [2].

Отличительная черта мировой
мультикультурной политики в том, что она имеет много общего во всех странах. Как правило, основными сферами приложения этой политики являются система образования и рынок труда. Но в каждой стране существуют различия в осуществлении стратегии мультикультурализма. Несмотря на разницу в стратегиях мультикультурализма, во всех странах, где в результате мирового исторического развития оказались на одной территории представители различных культур, наблюдается отказ (вынужденный или намеренный) от идеи доминирования одной культуры и единой межконфессиональной сферы, и тем самым формируются условия для взаимопонимания и толерантности, равных приоритетных прав для всех граждан. Эти практические проявления мультикультурных связей и отношений породили необходимость глубокого научного изучения мультикультурализма не только как проводимой политики, но и как социокультурного феномена, и - шире - как философской категории, порожденной эпохой глобализации.

Начавшееся

исследование мультикультурализма вызвало к жизни достаточное количество точек зрения мировых ученых о различных теориях культуры. Так, в российской, украинской философии признание получили деятельностная (М.С. Каган, Н. С. Злобин, В.М. Межуев), семиотическая (Ю.М. Лотман), системно-синергетическая (Э.С. Маркарян) теории культуры. Из европейских, северо-американских концепций, важных для исследования мультикультурализма, необходимо почеркнуть системно-функциональный метод исследования культуры (Б. Малиновский, Т. Парсонс), социальный акционализм (П. Бергер, Э. Гидденс), постмодернистскую концепцию культуры (Ж. Бодрийяр, Ж. Делез, Ф. Гваттари), психоаналитический метод исследования 
культуры (Э. Фромм, В. Райх, С. Жижек), экзистенциальную (Ортега-и-Гассет) концепцию культуры.

Теоретический анализ современной социокультурной ситуации, в рамках которой развивается феномен мультикультурализма, может быть основан на трудах Ж. Бодрийяра, Ж. Деррида, Ф. Гваттари, Ж.-Ф. Лиотара, Ю. Хабермаса, М. Фуко, И. Валлерстайна. Также, исследуя методологию мультикультурализма, необходимо основываться на работах украинских и российских ученых: Э. А. Баграмова, А. Бандурка, Б. Н. Бессонова, А. А. Борисова, А. И. Куропятника, В. С. Малахова, Н. М. Мамедовой, В. М. Межуева, О. А. Сергеевой, Б. Слющинского, К. Б. Соколова В. О. Тишкова, М. В. Тлостановой, Ю. Халиловой-Чуваевой, С. Червонной и др. При этом важно, что именно украинские ученые проблему мультикультурализма связывают с вопросами национальной идентичности и толерантности (И. Бубнов, Ю. Халилова-Чуваева, Р. Шульга).

Методологической базой изучения мультикультурализма как философской категории эпохи глобализации становятся теоретико-концептуальные положения современного гуманитарного знания: теории глобализации (С. Хантингтон, Ф. Фукуяма); самореализации и самоактуализации личности (А.Г. Асмолов, Берулава, А. Маслоу, К. Роджерс и др.); концепции: социокультурного пространства (П. Бурдье, Г. Зиммель, П. Сорокин); мультикультрализма и мультикультурных практик (Р. Бенедикт, М. Мид, Р. Брислин, Э. Холл), толерантности и толерантных отношений (О. Грелл, И. Карли, Дж. Лаурсен, В.А. Лекторский, Р. Портер, Л.В. Скворцов, М. Уолцер); синергетических подходов к изучению социальных вопросов (Ризниченко Г.Ю.); идентичности (Г. Дилигенский, Ю. Красин, А. Панарин, И. Кононов, С. Дацюк); ценностей и ценностных ориентаций (Е. Боринштейн, А. Кавалеров, А. Резник, А. Ручка); влияния социальной среды на развитие личности (Л.С. Выготский, Дж. Дьюи, П.Ф. Каптерев, Ж.Ж. Руссо). А также положения: о многомерности пространства развития личности (С.К. Бондырева, Б.С. Гершунский, В.Э. Штейнберг и др.); правах и обязанностях человека (Международная конвенция по правам человека, Декларация принципов толерантности, Конституция Украины, Законы Украины и др.).

В исследованиях ученых самых разных стран мультикультурализм предстает как в виде различных вариантов теории мультикультурного общества и обоснования мультикультуральных практик, так и в формах его теоретической критики. Важной является взаимосвязь мультикультурализма с проявлениями постмодерной парадигмы развития. Так, российский исследователь В. А. Мамонова считает, что мультикультурализму, как модели культуры, свойственны общие эстетические и философские установки постмодерна, т. к. «культура постмодерна, легитимировавшая множественность как субстантивное начало, закономерно рассматривает мультикультурализм как наиболее приемлемое культурное состояние общества, в котором толерантность, терпимость к культурной инаковости становятся общественно превалирующими ценностями» [3, с. 29-38].

В свою очередь, С. Бенхабиб, выступая с теоретическим принятием мультикультурализма, обращает внимание на низкую обоснованность универсальности западной культуры. Исследовательница отмечает моральную составляющую требований традиционных культур на получение равного статуса с западной культурой [4, с. 254-255]. Исследователи У. Кимлика и Ч. Кукастас предлагают конкретные модели социальной мультикультурализации, обосновывая их идейно $[5 ; 6]$. С. Жижек, С. М. Окин, Б. Кагарлицкий, напротив, указывают на слабые стороны мультикультурной теории и практики. Эти ученые определяют мультикультурализм как новую форму социальной реакционности. Так, Жижек полагает, что круг интересов мультикультурной этики ограничен политкорректным уважением к измышлению «иного», когда поиск универсальной истины порицается как форма культурного принуждения [7]. Д. Грей рассматривает проблематику мультикультурализма в ее связи с политическим плюрализмом. Поскольку культурные различия присущи всей истории человечества, то, по мнению исследователя, они являются чертой и современных обществ [8].

С. Хантингтон и П. Дж. Бьюкинен, напротив, рассматривают мультикультурализм как угрозу национальной идентичности и единству национального государства в современном мире. По их мнению, мультикультурализация общества приведет к умалению ценностей национальной культуры, обеспечивающих национальное единство и являющихся фундаментом национальной идентичности $[9$, с. 349; 10]. Исследователи А. Борисов и К. Гарибян отмечают потенциальную опасность мультикультурализма для существующего социального порядка $[11$, с. $8-9$; 12]. Э. Гидденс в своих работах отмечает угрозу перерастания мультикультурального проекта в культурный релятивизм. По его мнению, если для того, чтобы понять «иного», необходимо абстрагироваться от собственных убеждений и исторических ценностей, то как быть, если 
придется признать наиболее варварские традиции и обычаи? [13]. Позицию исследователя Р. Рорти по вопросу мультикультурализма можно охарактеризовать как прагматическую. Философ соглашается со сторонниками мультикультурализма относительного того, что теоретическое обоснование превосходства одних культурных ценностей над другими невозможно. Однако отсутствие такого обоснования не означает отказ от поиска форм солидарности. Рорти полагает, что поддержку национальной культуры можно аргументировать из соображений социальной прагматики, которые не нуждаются во внеисторическом обосновании [14, c. 179-209]. Схожую позицию занимает Ч. Тэйлор, указывающий на значимость этнических культурных традиций самих по себе для полноценного развития личности [15, с. 219-248].

Российский исследователь В. А. Тишков, в свою очередь, определяет мультикультурализм как «теорию, практику и политику неконфликтного сосуществования» различных этнических групп и, обращаясь в прошлое, отмечает, что национальная политика СССР уже содержала в себе мультикультуральные принципы. Следовательно, российская мультикультурная политика должна обратиться к советскому опыту [16, с. 35-48]. И. Валлерстайн также наблюдает противоречивые тенденции мультикультурализма. С одной стороны, по его мнению, происходит интернационализация культуры повседневной жизни (питание, одежда), a с другой стороны, отмечается устойчивый рост внимания ко всему культурно-неофициальному. В целом оценивая мультикультурализм положительно, исследователь подчеркивает его роль в общественном прогрессе [17, с.15-27].

Из нескольких приведенных точек зрения можно сделать вывод, что в мировой научной мысли еще не сформировалось однозначной оценки мультикультурализма как социального явления. В этой связи прогнозируется необходимость дальнейшего углубленного исследования проблемы мультикультурализма во всех его связях и несогласованностях, в виду того, что мультикультурализм сегодня не только теоретический концепт, но и объективно существующая социальная проблема, требующая как теоретического отражения, так и обусловленного практического решения. В связи с этим даже поверхностный взгляд на мультикультурализм позволяет выделить для изучения в нем несколько аспектов. Прежде всего, это аспект этнополитический, связанный с политикой государств, принимающих большие иммиграционные потоки. Во-вторых, это аспект культурно-исторический, выражающий специфику современных социокультурных процессов. Сюда следует добавить также аспект либерально-демократических свобод, расширение которых - один из путей решения проблем, возникающих в связи с увеличением культурного разнообразия.

Основная гипотеза этнополитического аспекта состоит в том, что этническая идентичность, межнациональные отношения и этнополитические процессы являются элементами этнополитического пространства, которое складывается обществом на определенной территории. Можно указать, что процессы глобализации актуализировали этнический фактор в международной жизни. При этом данную актуализацию можно свести к четырем основным проблемам: проблема коренных народов (аутентичной идентичности); выбор государств между политикой идентичности и политикой мультикультурализма; стремление малых народов и этнических меньшинств превратиться в фактор международной политики; общая политизация и актуализация этнического сознания. В этой связи встает вопрос о том, каким образом современное государство может действовать в ситуации, когда возникает угроза его целостности. Особенно это касается полиэтничных государств, где вопросы национальной политики являются во многом определяющими при разработке стратегии развития. Очевидно, это связано с тем, что в условиях стремительного формирования глобального социокультурного пространства приходит осознание того, что экономическую эффективность, экологическую устойчивость и культурное разнообразие невозможно поддерживать и развивать без регулирования процессов межкультурного взаимодействия.

$$
\text { Культурно-исторический }
$$

аспект исследования мультикультурализма исходит из тезиса о том, что мультикультурализм - феномен, соизмеримый с историей цивилизации. На протяжении многих веков его развитие шло вместе с прогрессивными социальными переменами, при этом основной смысл понятия мультикультурализма остается приблизительно одним и тем же, независимо от времени его формулировки. Особого внимания в связи с этим, на наш взгляд, заслуживает подход П. Штомпки. Ученый рассматривает мультикультурализм в двух измерениях. Во-первых, как «многообразие культур, успешных с точки зрения исторической оценки и сосуществующих на сегодняшний момент». Во-вторых, как идеологическую позицию, подразумевающую право разных обществ на свой собственный образ жизни и поддерживающую тезис об абсолютном равенстве всех культур [18, с. 255].

При изучении в рамках культурноисторического аспекта мультикультурализм трактуется в контексте культурного 
многообразия, означающего принятие и уважение индивидуальных черт и уникальности каждой культуры. Речь идет о демократическом сосуществовании как отдельных людей, так и групп, обладающих этнической идентичностью, собственными ценностями и традициями. Наиболее важно в этой связи, что культурное наследие представляет собой фактически главный способ существования культуры. То, что не входит в культурное наследие, перестает быть культурой и, в конечном счете, прекращает свое существование. После физической жизни людей культурное наследие остается для других поколений, выступая как общее достояние всего человечества, которое может быть таковым лишь при условии своего сохранения. Поэтому сохранение культурного наследия в любых культурных формах и поддержание разнообразия проявлений культуры в известной мере совпадает с сохранением общечеловеческого культурного развития в целом.

Исследование мультикультурализма в аспекте либерально-демократических свобод порождает два типа дискурса в современной научной теории: первый - «мультикультурализм есть часть демократии» и второй «мультикультурализм представляет собой отступление от общедемократических норм». В основе этого противоречия лежит возможная дихотомия между групповыми и индивидуальными правами. Совместное существование различных этнических групп в пределах одного государства неизменно создает требующие решения проблемы в сферах экономики, политики и культуры. Тем не менее, история и опыт ряда стран дают многочисленные примеры, показывающие, что в современном мире, несмотря на распространение идеологии этнического национализма, этническое многообразие само по себе не обязательно ведет к острым конфликтам и фрагментации общества. Существует ряд механизмов, обеспечивающих стабильность полиэтничного социума. Еще до недавнего времени наиболее распространенным из них был авторитарный или тоталитарный режим, который элиминировал политическую мобилизацию меньшинств и усмирял их сепаратистские наклонности. Но в современных демократических обществах такой подход не легитимен, поэтому и возникла политика мультикультурализма, которая призвана осуществлять учет групповых прав культурных меньшинств. Возможности решения вопроса о совместимости демократии и полиэтничности государства лежат в области самой природы демократии: является ли она действительно формой правления большинства, и какую роль должны в ней играть меньшинства. В зависимости от ответа можно прийти либо к мажоритарным вариациям полиэтнической демократии, либо к принципу сотрудничества этнических групп на основе распределения между ними власти. Сотрудничество этнических групп на основе распределения между ними власти является менее изученным подходом в современном мире, менее распространенным и поэтому данный подход нуждается в более внимательной разработке и свободном применении. На наш взгляд, этот способ синтеза демократии и мультикультурализма может явиться предпочтительным с точки зрения обеспечения стабильности социальных структур и сохранения общественных и личных свобод.

Национальные меньшинства, как аутентичные, так и иммиграционные, сегодня предъявляют к обществу абсолютно новые требования, в основе которых лежит желание «признания». Эти меньшинства желают участвовать в управлении государством наравне с титульным этносом и при этом жить согласно своим культурным нормам и традициям. Если следовать принципам демократии, такое требование логично. Очевидно, что если в государстве проживает большое количество коренных меньшинств и иммигрантов, то их представителям должны быть предоставлены места в органах управления. Однако, представители иммигрантов не могут достичь руководящих постов в силу того, что национальное большинство не позволяет им получить достаточное количество голосов, а если предоставить представителям национальных меньшинств упрощенные условия, то это порождает прямое нарушение демократии, положительную дискриминацию. Однако, такая ситуация должна быть преодолена, должны предприниматься попытки политического равенства. Так как политическое и социальное равенство являются в определенной степени идеальными явлениями, национальные меньшинства могут достигнуть их только через подтверждение и развитие своих культурных особенностей. Из этого следует, что признание и равенство всех национальностей, проживающих на территории государства, есть, прежде всего, обязанность самого государства как института, формирующего базу демократии. Функционирование мультикультурных связей порождает тезис о возможности формирования состояния взаимопримирения на время сотрудничества и механизмов, которые создают возможность совместной жизнедеятельности между индивидами с антагонистическими убеждениями.

Подытоживая анализ методологических аспектов исследования феномена мультикультурализма, необходимо признать, что принципиальную основу методологии 
мультикультурализма составляют принципы объективности, историзма, единства теории и практики; неделимости исторического и логического, целостности системно-структурного и генетического подходов. Как первоочередные, могут использоваться общенаучные методы исследования: анализ и синтез, индукция и дедукция; метод восхождения от абстрактного к конкретному. Всеобщим для научных разработок является следование принципам синергетики. Характерными для рассуждений о мультикультурализме являются комплексные методы: сравнительно-сопоставительный анализ философской, культурологической, социальнопедагогической и социально-психологической литературы, метод междисциплинарного анализа категорий, метод анализа логикометодологических оснований. Специфическими непосредственно для исследования мультикультурализма являются аксиологический, акмеологический, исторический, гносеологический, социально-философский, структурно-функциональный, ксенологический методы исследования.

Рассмотренные выше методологические подходы и аспекты исследования усматривают мультикультурализм необходимым для прогрессивных изменений в глобальном социокультурном пространстве. Несформированность и несоблюдение парадигмы мультикультурализма ведет к развитию процессов, которые характеризуются угрозой социальной идентичности, столкновением несовместимых интересов, потребностей, ценностей. Разнообразие методологических подходов к изучению мультикультурализма свидетельствует о том, что данное явление действительно является одним из самых сложных и многоаспектных феноменов современности.

Многообразие подходов демонстрирует значительную противоречивость исследуемого феномена. Несмотря на обилие точек зрения на мультикультурализм, можно признать, что именно применительно к социокультурной сфере данное явление недостаточно исследовано. Речь идет о рассуждениях на стыке социальнофилософских, социально-педагогических, социально-психологических, социальноправовых подходов. Необходимым есть выяснение оснований мультикультурности как коммуникативного свойства личности, механизмов формирования мультикультурного поведения и вопросов толерантности в мультикультурно-правовом взаимодействии, а также расширение возможности использования мультикультурного взаимодействия в рамках педагогики и конфликтологии. В дальнейшие исследовательские задачи должно входить сопоставление установки на мультикультурность конкретной личности с базовыми константами всеобщей и индивидуальной культуры.

Современный

многомерный, мультикультурный и многоконфессиональный мир реализует свои духовные и материальные потребности через многочисленные каналы, из которых наиболее существенным и убедительным в плане направленного воздействия является социокультурное пространство. Социокультурная сфера как ведущий общественный феномен самым активным образом реагирует на мировые тенденции глобализационного плана и влияет на международные, национально-государственные и региональные процессы посредством личностного самоосуществления индивида. В рамках функционирования современного общества возникает мультикультурный подход к построению социокультурных концепций как основы конструирования нового качества культуры.

Корректное,

методологически последовательное изучение политики и практики мультикультурализма с учетом характерных особенностей любой страны может способствовать признанию самоценности культурного разнообразия и сбережению ценностей и традиций самых разных культурных групп. В целом концепция мультикультурализма противостоит дискриминации, угнетению и подчеркивает индивидуальное достоинство, присуще всем. Эта задача является приоритетным условием развития современного мира и обеспечения мирного сосуществования в нем множества народов и культур.

При корректном исследовании мультикультурализма становится ясным, что культурная и этническая плюральность, как правило, приводит не к вражде, а к согласию. С точки зрения мультикультурализма важно не только то, какую иммиграционную политику проводит та или иная страна, но и то, как эти проблемы отражены в научном дискурсе, и какую официальную позицию по этой проблеме высказывают правящие круги. При этом необходимо отметить, что введение мультикультурной политики в различных государствах было ориентировано на решение неодинаковых проблем. Кроме того, любая мультикультуралистическая модель с необходимостью строится на фундаменте ценностей, идей и идеалов конкретного общества. Поэтому и мультикультурные практики всегда будут существенно отличаться в каждой стране.

Последовательное методологическое рассмотрение мультикультурализма приводит к тезису, что единой стратегии мультикультурализма нет и не может быть не только по экономическим, политическим, 
социальным причинам, но и - главное - по характеру ценностных установок личностей, групп, государств, что во многом определяет в целом характер глобального социокультурного развития. Представленная методология исследования мультикультурализма ведет к $\begin{array}{llll}\text { осмыслению } & \text { т. } & \text { н. }\end{array}$ мультикультурализма» как парадигмы эпохи глобализации. Мультикультурализм, рассмотренный средствами указанной методологии, усматривается как категория, предлагающая некие универсальные ценности, принципы для всех стран и народов, но при этом каждый субъект мультикультурализма должен разрабатывать и вводить свою персональную стратегию достижения и использования мультикультурных практик с учетом собственной специфики. Однако при всем этом можно признать, что в настоящее время ни одна из мультикультурных стран не достигает такого идеала.
Представленные данные подчеркивают, что функционирование мультикультурной парадигмы определяется введением в социокультурную сферу отношения к человеку, как к ценности, в интегративном соединении его социокультурных характеристик. Проявление мультикультурных взаимоотношений сегодня - это реализация модели поведения в социокультурном пространстве глобализации. Создание моделей мультикультурного взаимодействия субъектов социокультурного пространства может быть заложено только в рамках новых, ориентированных в сторону глобализированного социокультурного пространства, социальнофилософских концепций, что отражает синергетический подход к осмыслению и построению основ социокультурного развития. Несомненно, что изучение этой проблематики и наработки по формированию мультикультурной парадигмы для социокультурного пространства большинства стран мира представляет стратегически значимую цель.

\section{References:}

1. Panarin AS (2003) Strategicheskaya nestabilnost v XXI veke. M., pp. 427-428.

2. Muravev YA (1999) Antinomii multikulturalizma / Y. A. Muravev. M.: IEA RAN. 112 p.

3. Mamonova VA (2007) Multikulturalizm: raznoobrazie i mnozhestvo Tekst. Intelros. №2. pp. 29-38.

4. Benhabib Seyla (1996) Democracy and Difference. Princeton, 1996. pp.180-185, 254-255, 282-283.

5. Kimlika U (2010) Sovremennaya politicheskaya filosofiya: vvedenie. Moscow: Izd. dom Gos. un-ta. - Vyisshey shkolyi ekonomiki. 592 p.

6. Kukatas C (2011) Liberalnyiy arhipelag. Teoriya raznoobraziya i svobodyi. Moscow: Myisl. 482 p.

7. Zhizhek S (2003) 13 opyitov o Lenine. Moscow: Ad Marginem. 255 p.

8. Grey D (2003) Pominki po Prosvescheniyu. Politika i kultura na zakate sovremennosti. Moscow: Praksis. 368 p.

9. Byukenen PD (2007) Na krayu gibeli. [per. s angl.]. - Moscow: AST. pp. 349.

10. Hantington S (2003) Stolknovenie tsivilizatsiy, per. $\mathrm{s}$ angl. T. Velimeeva, Y. Novikova. Moscow: OOO «Izdatelstvo AST». 605 p.

11. Borisov AA (2003) Multikulturalizm: Amerikanskiy opyit i Rossiya. Moscow. Izd-vo Aspekt-press. pp. 8-9, 23.
12. Garibyan K (2014) Razmyishleniya o perspektivah realizatsii politicheskogo proekta multikulturalizma $\mathrm{v}$ postsovetskom prostranstve: da ili net? / Garibyan K. Available:

http://www.intelros.ru/pdf/gender_issledovaniy a/2008 1 8/18.pdf (Accessed: 26.09.2015).

13. Giddens E (2005) Sotsiologiya. K. Berdsoll: Per. s angl. Izd. 2-e, polnostyu pererab. i dop. Moscow: Editorial URSS. 632 p.

14. Rorti R (2005) Postmodernistskiy burzhuaznyiy liberalism. Logos. Izbrannoe, 1991-2005. T. 2., Moscow. pp. 162-259.

15. Teylor C (1998) Peresechenie tseley: Spor mezhdu liberalami i kommunitaristami. Sovremennyiy liberalizm: Rolz, Byorlin, Dvorkin, Kimlika, Sendel, Teylor, Uoldron. M.: Dom intellektualnoy knigi, Progress-Traditsiya. pp. 219-248.

16. Tishkov VA (2002) Teoriya i praktika multikulturalizma. Multikulturalizm i transformatsiya postsovetskih obschestv. Pod red. V.S. Malahova, V.A. Tishkova. Moscow. pp. 35-48.

17. Vallerstayn I (2006) Vozmozhna li vsemirnaya kultura? Hrestomatiya po kulturologii pod red. Kravchenko A. I. Moscow. pp. 15-27.

18. Sztompka P (2005) Socjologia. Krakow. - pp. 255. 